\title{
Adjuvant chemotherapy for poor-responders to neoadjuvant therapy in locally advanced rectal cancer: does it improve the prognosis?
}

KHADIJA DARIF ( $\sim$ khadija_sky@hotmail.fr)

Department Of Medical Oncology, University Hospital Center Hassan II

\section{ZINEB BENBRAHIM}

Department Of Medical Oncology, University Hospital Center Hassan II

\section{JIHANE CHOUEF}

Department Of Medical Oncology, University Hospital Center Hassan II

\section{ZAYNAB MAHDI}

Epidemiology Department University Hospital Center Of Tanger

ADIL NAJDI

Epidemiology Department University Hospital Center Of Tanger

\section{LAILA CHBANI}

Anatomopathology Department, University Hospital Center Hassan II. FEZ

\section{ELBACHIR BENJELLOUN}

Department Of Visceral Surgery,University Hospital Center Hassan II,Fez

\section{KARIM IBN MAJDOUB}

Department Of Medical Oncology, University Hospital Center Hassan II

KHALID MAZAZ

Department Of Visceral Surgery,University Hospital Center Hassan II,Fez

NADA LAHMIDANI

Department Of Gastroenterology University Hospital Center Hassan II

\section{MOHAMMED EL ABKARI}

Department Of Gastroenterology University Hospital Center Hassan II

\section{LAMIAE AMAADOUR}

Department Of Medical Oncology, University Hospital Center Hassan II

\section{KARIMA OUALLA}

Department Of Medical Oncology, University Hospital Center Hassan II

\section{FZ EL M'RABET}

Department of Medical Oncology , University Hospital Center Tanger

\section{SAMIA ARIFI}

Department Of Medical Oncology, University Hospital Center Hassan II 
Department Of Medical Oncology, University Hospital Center Hassan II

\section{Research Article}

Keywords: rectal cancer, adjuvant chemotherapy, poor responders

Posted Date: February 24th, 2021

DOI: https://doi.org/10.21203/rs.3.rs-215233/v1

License: (c) (i) This work is licensed under a Creative Commons Attribution 4.0 International License. Read Full License 


\section{Abstract}

Background: Colorectal cancer is the first cause of cancer death in developed countries. Although colon and rectal cancers are frequently grouped as a single disease entity, these malignancies have important differences in treatment approaches ; The preoperative radio-chemotherapy combination has become the standard for tumors of the middle and lower rectum, improving local control. But unlike colon cancer, currently there is no compelling evidence of the benefit of adjuvant chemotherapy in rectal cancer. This study examines the role of adjuvant chemotherapy after a neoadjuvant treatment and chirurgy in localy advanced rectal cancer, especially in poor responders to neoadjuvant therapy.

Patients and Methods: Using the medical files collected at the medical oncology department at the Hassan II Hospital Center in Fez, Morocco; patients with rectal cancer diagnosed in 2014 through 2019 who received neoadjuvant CRT(concomitant radio chemotherapy) and surgery with or without AC(adjuvant chemotherapy) were identified. Kaplan-Meier analysis, log-rank tests were used to assess survival. Results: A total of 90 patients were identified; 70 received AC and 20 did not (observation [OBS] group). Median overall survival(OS) of the general population was 40 months, $\mathrm{Cl} 95 \%=[25-56]$, the median disease-free survival (DFS) was 17 months,Cl 95\% = [7-26]. In the analysis of survival according to the ypT and ypN subgroups: the median OS in the ypT1-2 and ypNO subgroup was higher than in the урT3-4 or ypN + group (40 months vs 33 months and 44 months vs. 31 consecutive months); DFS was also better in the ypT1-2 and ypN0 group (29 months vs. 11 months $(p=0.05)$ and 29 months vs. 13 months respectively).The median OS was 40 months for AC and 23 months for OBS ( $p=0.036)$, by against there was no significant improvement in recurrence-free survival.

Conclusions: In this population of patients with LARC (localy advanced rectal cancer) treated with neoadjuvant CRT and surgery,

\section{Background}

Rectal cancer is the second most frequent digestive cancer in the world [2]. It is the leading cause of death in developed countries [1-3]. Its frequency continues to increase causing a real problem of diagnosis and management. However, its incidence in Morocco remains lower than that of Western countries.

The preoperative radio-chemotherapy combination has become the standard treatement for tumors of the middle and lower rectum, improving local control but not overall survival or survival without metastatic relapse.

Unlike colon cancer, curently there is no compelling evidence of the benefit of adjuvant chemotherapy (AC) in rectal cancer. Current recommendations for $\mathrm{AC}$ of rectal cancer are based on the evidence extrapolated from studies in colon cancer; However, despite the limited data supporting the use of AC in localy advanced rectal cancer (LARC), national oncology guidelines, including those published by the NCCN, recommend a total duration of 6 months of perioperative systemic therapy for LARC. $(7,8)$ 
The prognosis of patients with more advanced rectal cancers (stage II and III, T3 / 4, lymph node negative or positive) differs from the early stages (4) in fact the local recurrence rates are higher in the advanced stages $(13 \%$ vs. $5 \%)$ and 5 -year survival is markedly reduced (35\% vs. $90 \%)[5,6]$. The purpose of this study was to determine the role of adjuvant treatment as a prognostic factor in patients with LARC treated by neoadjuvant concomitant radio chemotherapy (CRT) followed by surgery.

\section{Patients And Methods}

This is a descriptive and analytical retrospective study; performed in the Medical Oncology Department at the University Hassan II Center, for a period of 6 years. It includes all patients covered between January 1 , 2014 and December 30, 2019, with rectal cancer received concurrent CRT followed by surgery with or without AC.

The aims of this analysis is to describe the epidemiological, clinical, anatomo-pathological and therapeutic profile of localy advanced rectal cancer; to determine the importance of adjuvant treatment as prognostic factor especially in poor responders to neoadjuvant traitement and analysis of overall survival and to compare it with the exisiting data in the literature.

\section{Statistical Analysis:}

The statistical analysis included several steps : Descriptive analysis of the global population using several variants: epidemiological characteristics of the general population: age, sex, characteristics of the tumor: location (high, middle or low rectum), differentiation, ypTNM stage ; Analysis of survival according to the ypT and ypN subgroups; and comparison of survival between the 2 groups AC vs observation (OBS).

The end- points were overall survival (OS) and disease-free survival (DFS), calculated from the diagnosis date to the date of death, DFS and OS were estimated using the Kaplan-Meier method, and comparisons were performed using the log-rank test.

\section{Results}

\section{Patient Characteristics:}

Out of all 300 rectum cancer cases, we collected 90 patients who were diagnosed with adenocarcinoma rectum were treated with $\mathrm{CRT}$ followed by surgery with or without $\mathrm{AC}$. In the analysis of the overall study population: The median age was $59 \pm 14.14$ years with ranges "24-86 years". There was a slight predominance of women, with a sex ratio M/F of 0.87 (47\% men and $52 \%$ women). Endoscopic examination showed that the tumor was located in the middle rectum in $47 \%$ of cases, and $43 \%$ in the lower rectum. The biopsy of tumors found that the liberkunian adenocarcinoma was well differentiated in $70 \%$ of the cases, moderately differentiated in $28 \%$ and in $2 \%$ poorly differentiated.(table 1 ) 
All patients received concomitant radiochemotherapy with CAP 50 protocol followed by tumor resection. the anatomopathological examination allowed to classify the patients according to the yPTNM as follows: $69 \%$ of ypT3-4 and $48 \%$ classified as ypN1-2. (table 1 ). After surgery, $80 \%$ of patients received adjuvant chemotherapy such as XELOX or FOLFOX and $20 \%$ of patients were placed under OBS.

\section{Survival Outcomes:}

The median OS of the general population was 40 months, $95 \% \mathrm{Cl}=[25-56]$, and the median DFS was 17 months, $95 \% \mathrm{Cl}=[7-26]$. (Figure1 )

In the analysis of survival according to the ypT and ypN subgroups: the median OS in the ypT1-2 and ypNO subgroups was higher than in the ypT3-4 or ypN + subgroups: 40 months vs 33 months $(p=0.3)$ and 44 months vs 31 months respectively $(p=0.6)$ (figure 2); DFS was also better in the ypT1-2 and ypN0 group : 29 months vs. 11 months $(p=0.05)$ and 29 months vs. 13 months respectively $(p=0.2)$. (figure 3 , 4)

The analysis of survival according to AC demonstrated a significant improvement in the median OS in the group that has received AC of 40 months vs. 23 months in the monitoring group ( $p=0.036)$; however, there was no significant improvement in DFS: 18 mois vs 17 mois $(p=0,14)$.( Figure 2$)$

All stages (whatever the ypT and ypN) benefit from AC without any significant difference between the different subgroups. But by comparing the ypT and ypN subgroups in patients who received adjuvant CMT, we find that survival remains better in the T1-2 and N0 groups; we found in Table 2 : in patients who received AC : the median of OS in ypT1-2 and ypNO sub groups was 54 months and 48 months vs 39 and 34 months in ypT3-4 and ypN+ subgroups .(table 2)

\section{Discussion}

Currently, despite the reduced risk of local recurrence, the risk of metastatic recurrence after rectal cancer surgery remains in the order of $20 \%$ to $60 \%$ depending on the initial TNM stage. In recent therapeutic trials (Sauer, 2004; Kapiteijn, 2001; Gérard, 2006; Bosset, 2006; Sebag-Montefiore, 2009; Gérard, 2012) this risk for T3 or T4 rectal cancers remained at 32 to $38 \%(9)$.

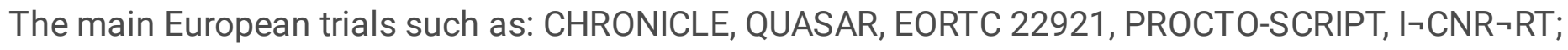
recruiting 3143 patients with stage II and III rectal cancer studied the role of adjuvant chemotherapy after chemotherapy and neoadjuvant surgery, four of the five trials reported negative results and only the QUASAR study found significantly increased survival in the postoperative chemotherapy group (10). 
EORTC study 22921 did not show an improvement in overall survival for patients treated with preoperative radiochemotherapy followed by surgery, followed by 4 courses of adjuvant chemotherapy with 5FU,with a follow-up of 10 years, this adjuvant chemotherapy did not provide any gain in relapse-free or overall survival (11). In the Italian Trial ICNRRT, 635 patients were treated with preoperative chemoradiotherapy and then were randomised into observation and postoperative chemotherapy groups No difference in overall and diseasefree survival was reported at 5 and 10 years of follow up. $(10,12)$

However, the QUASAR trial suggests that adjuvant chemotherapy with fluoropyrimidines reduces the risk of metastatic recurrence and improves survival after curative surgery for stage II or III rectal cancer, including after preoperative RT. This benefit appears to be similar to that observed in colon cancer.(13)

In 2014 the phase II trial ADORE (23)(ADjuvant Oxaliplatin in REctal cancer), the only trial that showed a survival benefit for AC in stage II,compared CA by 5 -FU + folinic acid with treatment with modified FOLFOX6 in 321 patients operated after RCT, stage II-III with R0 resection [40]. After a median follow-up of 38.2 months, the SSR and OS at 3 years were significantly greater in the modified FOLFOX6 arm ( $71.6 \%$ vs $62.9 \%, p=0.047$ and $95.0 \%$ vs $85,7 \%, p=0.036$ respectively).

In addition, the meta-analysis performed by Petrelli et al in 2015 [14], (16 randomized and nonrandomized studies; a total of 5457 patients) showed that adjuvant chemotherapy significantly improved disease-free and overall survival and rates of distant metastases. However, the stratified analyzes objected that the benefit was observed only in non-studies where participants were often younger, had negative lymph nodes and had a good response to preoperative chemotherapy. (10)

In the same way ; findings of our study showed that the use of AC was associated with improvement in OS ; as well as the analysis of the subgroups according to the yPTNM classification found that the ypT12 or N0 subgroups have better survival than the ypT3-4 and ypN + subgroups, even if the results are not statically significant, but we tend to conclude that AC certainly improves the survival of patients even after treatment neoadjuvant but does not improve the prognosis of poor responders which makes the histological response the most important prognostic factor.

Our results agree perfectly with those of a pooled analysis of five randomized controlled trials in the United States (15), the analysis included 3791 patients with rectal cancer, overall 5-year survival was better in the early stages ( T1-2 90\%, vs T3 4N0 60\%, T4N1 30\%). Likewise, the EORTC 22921 trial showed that only patients with a low stage (ypTN0-2) received adjuvant chemotherapy, unlike patients with ypTN3-4 [16].

Two other studies by De Stefano et al [17] and Janjan et al [18] also showed that the group of poor responders to neoadjuvant treatment did not benefit from $A C$, unlike patients who responded to preoperative chemoradiotherapy the benefit of AC was observed. Two other studies also $[19,20]$ have shown that patients with a good response to preoperative chemotherapy had excellent 5-year survival (90\% survival), whether or not adjuvant chemotherapy was administered [10]. 
Also in a very recent study (PRODIGE23 trial) presented at ASCO 2020, a new concept emerged that of Total Neoadjuvant Therapy (TNT) including neoadjuvant chemotherapy, followed by CRT, surgery then AC: 460 patients with locally advanced rectal cancer First chemotherapy for 3 months of Folfirinox (6cycles) followed by CRT then surgery followed by adjuvant chemotherapy 3 months of FOLFIRINOX vs standard RCC: The perioperative TNT strategy using FOLFIRINOX trichimotherapy reduces the risk of metastatic relapse by $31 \%$ at 3 years with an increased rate of complete pathological response, which makes TNT a New standard for T3-T4, N +.(24)

Therefore these different studies suggest that not all patients with rectal cancer benefit from adjuvant chemotherapy and that only certain groups can respond to the treatment; The histological response after neoadjuvant treatment: the degree of penetration of the intestinal wall and lymph node involvement has been shown to be one of the most important predictors of local relapse, distant metastasis and survival.

The panel of National Comprehensive Cancer (NCCN) recommends adjuvant therapy in patients with stage II/III rectal cancer. (25)

\section{Conclusion}

The low rate of patients who achieve pCR after adjuvant therapy remains low (approximately 10 to $20 \%$ of all patients with rectal cancer) $(21,22)$ which explains the lack of prospective studies to assess the effect of ACT. Without forgetting the potential for toxicity linked to adjuvant treatment, which makes compliance and therefore adherence to treatment mediocre. A meta-analytical approach with a larger number of patients is necessary to properly define the role of this CA.

\section{Declarations}

- Ethical Approval and Consent to participate : taken

- Consent for publication not applicable

- Competing interests : I declare no link of interest

- Availability of supporting data : all data is available

- Funding : I do not declare any funding

- Authors' contributions : The corresponding author wrote the article, all other authors participated in the review of the article

- statement attesting to informed consent for study participation :

- All methods were carried out in accordance with relevant guidelines and regulations.

- All experimental protocols were approved by Hospital University Center Department Of Medical Oncology Hassan II FEZ ; informed consent from all subjects : Not applicable :It's a retrospective Study

- Informed consent for experiments involving human : Not applicable. 
- Acknowledgements : I thank all the participants to develop this work

\section{References}

1. Khuhaprema T, Srivatanakul P. Colon and Rectum Cancer in Thailand: An Overview. Jpn J ClinOncol. 2008;38(4):237-43. [PubMed] [Google Scholar]

2. Abid L. Épidémiologie des cancers en Algérie: problématique des registres des cancers. J Afr Cancer. 2009;1(2):98-103. [Google Scholar]

3. Potter JD, Slattery ML, Bostick RM, et al. Colon Cancer: a Review of the Epidemiology. Epidemiol Rev. 1993;15(2):499-545. [PubMed] [Google Scholar]

4. Milinis K, Thornton M, Montazeri A, Rooney PS. Adjuvant chemotherapy for rectal cancer: Is it needed? World J Clin Oncol 2015; 6(6): 225-236 Available from: URL: http://www. wjgnet.com/22184333/full/v6/i6/225.htm

5. Gunderson LL, Sargent DJ, Tepper JE, Wolmark N, O'Connell MJ, Begovic M, Allmer C, Colangelo L, Smalley SR, Haller DG, Martenson JA, Mayer RJ, Rich TA, Ajani JA, MacDonald JS, Willett CG, Goldberg RM. Impact of $\mathrm{T}$ and $\mathrm{N}$ stage and treatment on survival and relapse in adjuvant rectal cancer: a pooled analysis. J Clin Oncol 2004; 22: 1785-1796 [PMID: 15067027 DOI:

$10.1200 / J C 0.2004 .08 .173]$ 《

6. Gunderson LL, Callister M, Marschke R, Young-Fadok T, Heppell J, Efron J. Stratification of rectal cancer stage for selection of postoperative chemoradiotherapy: current status. Gastrointest Cancer Res 2008; 2: 25-33 [PMID: 19259319] 区

7. Benson AB III, Venook AP, Al-Hawary MM, et al. NCCN Clinical Practice Guidelines in Oncology: Rectal

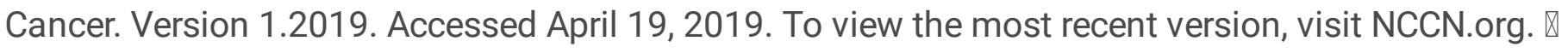

8. Survival Advantage With Adjuvant Chemotherapy for Locoregionally Advanced Rectal Cancer: A Veterans Health Administration Analysis Daphna Y. Spiege J Natl Compr Canc Netw 2020;18(1):5258 doi: 10.6004/jnccn.2019.7329

9. *Cotte E, Artru P, Christou N, Conroy T, Doyen J, Fabre J, Legoux JL, Hoeffel C, Léonard D, Meillan N, Paix A, Pioche M, Rivin Del Campo E, Vendrely V. «Cancerdu rectum ». Thésaurus National de Cancérologie Digestive, Mars 2019, [En ligne] [http://www.tncd.org]

10. Adjuvant chemotherapy for rectal cancer: Is it needed? Kristijonas Milinis, Michael Thornton, Amir Montazeri, Paul S Rooney, World J Clin Oncol 2015 December 10; 6(6): 225-236 ISSN 2218-4333

11. Bosset JF, Calais G, Mineur L, Maingon P, Stojanovic-Rundic S, Bensadoun RJ, Bardet E, Beny A, Ollier JC, Bolla M, Marchal D, Van Laethem JL, Klein V, Giralt J, Clavère P, Glanzmann C, Cellier P, Collette L. Fluorouracil-based adjuvant chemotherapy after preoperative chemoradiotherapy in rectal cancer: long- term results of the EORTC 22921 randomised study. Lancet Oncol 2014; 15: 184-190 [PMID: 24440473 DOI: 10.1016/ S1470-2045(13)70599-0] 《

12. Sainato A, Cernusco Luna Nunzia V, Valentini V, De Paoli A, Maurizi ER, Lupattelli M, Aristei C, Vidali C, Conti M, Galardi A, Ponticelli P, Friso ML, lannone T, Osti FM, Manfredi B, Coppola M, Orlandini C, 
Cionini L. No benefit of adjuvant Fluorouracil Leucovorin chemotherapy after neoadjuvant chemoradiotherapy in locally advanced cancer of the rectum (LARC): Long term results of a randomized trial (I-CNR-RT). Radiother Oncol 2014; 113: 223-229 [PMID: 25454175 DOI: 10.1016/j.radonc.2014.10.006] 区

13. Gray R, Barnwell J, McConkey C, Hills RK, Williams NS, Kerr DJ. Adjuvant chemotherapy versus observation in patients with colorectal cancer: a randomised study. Lancet 2007; 370: 2020-2029 [PMID: 18083404 DOI: 10.1016/S0140-6736(07)61866-2]

14. Petrelli F, Coinu A, Lonati V, Barni S. A systematic review and meta-analysis of adjuvant chemotherapy after neoadjuvant treatment and surgery for rectal cancer. Int J Colorectal Dis 2015; 30: 447-457 [PMID: 25433820 DOI: 10.1007/s00384-014-2082-9] ه

15. Gunderson LL, Sargent DJ, Tepper JE, Wolmark N, O’Connell MJ, Begovic M, Allmer C, Colangelo L, Smalley SR, Haller DG, Martenson JA, Mayer RJ, Rich TA, Ajani JA, MacDonald JS, Willett CG, Goldberg RM. Impact of T and N stage and treatment on survival and relapse in adjuvant rectal cancer: a pooled analysis. J Clin Oncol 2004; 22: 1785-1796 [PMID: 15067027 DOI: 10.1200/JCO.2004.08.173] ه

16. Bosset JF, Collette L, Calais G, Mineur L, Maingon P, Radosevic- Jelic L, Daban A, Bardet E, Beny A, Ollier JC. Chemotherapy with preoperative radiotherapy in rectal cancer. N Engl J Med 2006; 355: 1114-1123 [PMID: 16971718 DOI: 10.1056/NEJMoa060829]

17. De Stefano A, Moretto R, Bucci L, Pepe S, Romano FJ, Cella AC, Attademo L, Rosanova M, De Falco S, Fiore G, Raimondo L, De Placido S, Carlomagno C. Adjuvant treatment for locally advanced rectal cancer patients after preoperative chemoradiotherapy: when, and for whom? Clin Colorectal Cancer 2014; 13: 185-191 [PMID: 25080847 DOI: 10.1016/j.clcc.2014.05.004]

18. Janjan NA, Crane C, Feig BW, Cleary K, Dubrow R, Curley S, \Vauthey JN, Lynch P, Ellis LM, Wolff R, Lenzi R, Abbruzzese J, Pazdur R, Hoff PM, Allen P, Brown T, Skibber J. Improved overall survival among responders to preoperative chemoradiation for locally advanced rectal cancer. Am J Clin Oncol 2001; 24: 107-112 [PMID: 11319280 DOI: 10.1097/00000421-200104000-00001] 区

19. Fietkau R, Barten M, Klautke G, Klar E, Ludwig K, Thomas H, Brinckmann W, Friedrich A, Prall F, Hartung G, Küchenmeister U, Kundt G. Postoperative chemotherapy may not be necessary for patients with ypNO-category after neoadjuvant chemoradiotherapy of rectal cancer. Dis Colon Rectum 2006; 49: 1284-1292 [PMID: 16758130 DOI: 10.1007/s10350-006-0570-x] 》

20. Kiran RP, Kirat HT, Burgess AN, Nisar PJ, Kalady MF, Lavery IC. Is adjuvant chemotherapy really needed after curative surgery for rectal cancer patients who are node-negative after neoadjuvant chemoradiotherapy? Ann Surg Oncol 2012; 19: 1206-1212 [PMID: 21935748 DOI: 10.1245/s10434011-2044-1] $\otimes$

21. Sainato A, Cernusco Luna Nunzia V, Valentini V, De Paoli A, Maurizi ER, Lupattelli M, Aristei C, Vidali C, Conti M, Galardi A, Ponticelli P, Friso ML, lannone T, Osti FM, Manfredi B, Coppola M, Orlandini C, Cionini L. No benefit of adjuvant Fluorouracil Leucovorin chemotherapy after neoadjuvant chemoradiotherapy in locally advanced cancer of the rectum (LARC): Long term results of a 
randomized trial (I-CNR-RT). Radiother Oncol 2014; 113: 223-229 [PMID: 25454175 DOI:

10.1016/j.radonc.2014.10.006] 区

22. Gray R, Barnwell J, McConkey C, Hills RK, Williams NS, Kerr DJ. Adjuvant chemotherapy versus observation in patients with colorectal cancer: a randomised study. Lancet 2007; 370: 2020-2029 [PMID: 18083404 DOI: 10.1016/S0140-6736(07)61866-2] \&

23. Hong YS, Nam BH, Kim KP, et al (2014) Oxaliplatin, fluorouracil, and leucovorin versus fluorouracil and leucovorin as adjuvant chemotherapy for locally advanced rectal cancer after preoperative chemoradiotherapy (ADORE): an open-label, multicentre, phase 2, randomised controlled trial. Lancet Oncol 15: 1245-53

24. Thierry Conroy and Al Total neoadjuvant therapy with mFOLFIRINOX versus preoperative chemoradiation in patients with locally advanced rectal cancer: Final results of PRODIGE 23 phase III trial, a UNICANCER GI trial. DOI: 10.1200/JCO.2020.38.15_suppl.4007 Journal of Clinical Oncology 38, no. 15_suppl (May 20, 2020) 4007-4007. Published online May 25, 2020.

25. RECTAL CANCER Version 1.2021 @ 2020 National Comprehensive Cancer Network@ (NCCN@)

\section{Tables}

Table 1: Patient and tumor characteristics of general population

\begin{tabular}{|l|l|}
\hline \multicolumn{1}{|c|}{ Caracteristic } & All patients \% \\
\hline Age,year & \\
Median & 59 \\
IQR & 14.4 \\
\hline Sex & 47 \\
Male & \\
female & 52 \\
& \\
\hline Tumor site & \\
Middle Rectum & 47 \\
Low Rectum & 43 \\
\hline Differenciation & \\
well differentiated & 70 \\
moderately differentiated & 28 \\
poor differentiated & 2 \\
\hline ypTNM & \\
T1-T2 & 31 \\
T3-T4 & 69 \\
N0 & 52 \\
N+ & 48 \\
\hline
\end{tabular}

Table 2 : Comparison of mean overall survival between the ypT and ypN subgroups in the two groups $\mathrm{AC}$ and $\mathrm{OBS}$ 


\begin{tabular}{|c|c|c|c|}
\hline Stage & Adju & \multicolumn{2}{|c|}{ nftreatment } \\
\hline \multicolumn{4}{|c|}{ урТ (1-2) / (3-4) } \\
\hline \multirow[t]{2}{*}{ урТ1-Т2 } & OBS & 16 & \multirow{2}{*}{$\mathrm{p}=0.058$} \\
\hline & $\mathrm{AC}$ & 52 & \\
\hline \multirow[t]{2}{*}{ урТ3-Т4 } & OBS & 21 & \multirow[b]{2}{*}{$\mathrm{p}=0,5$} \\
\hline & $\mathrm{AC}$ & 39 & \\
\hline \multicolumn{4}{|c|}{ ypN+/- } \\
\hline \multirow[t]{2}{*}{ ypNO } & OBS & 18 & \multirow{2}{*}{$\mathrm{p}=0.06$} \\
\hline & $\mathrm{AC}$ & 48 & \\
\hline \multirow[t]{2}{*}{ ypN1-N2 } & OBS & 25 & \multirow{2}{*}{$\mathrm{p}=0.7$} \\
\hline & $\mathrm{AC}$ & 34 & \\
\hline
\end{tabular}

Figures
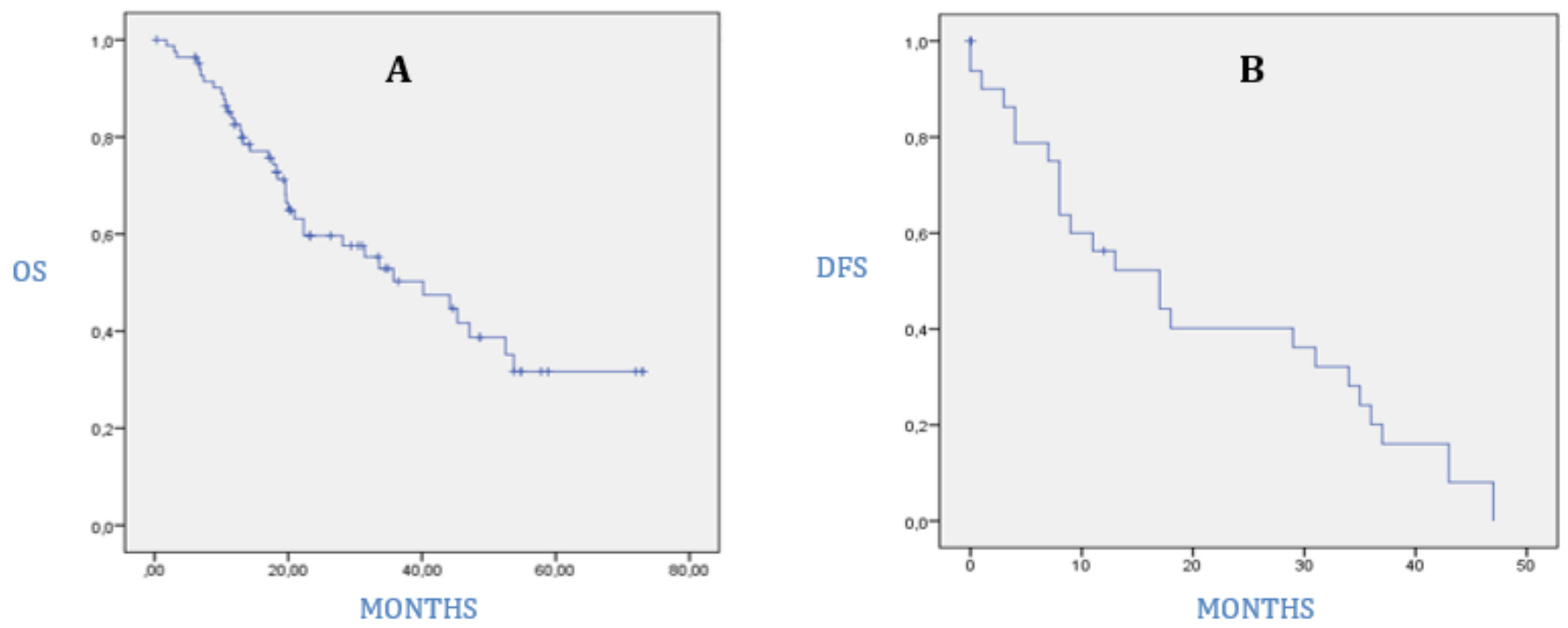

Figure 1 
A : Overall survival (OS) and B: free disease survival (DFS) of general population

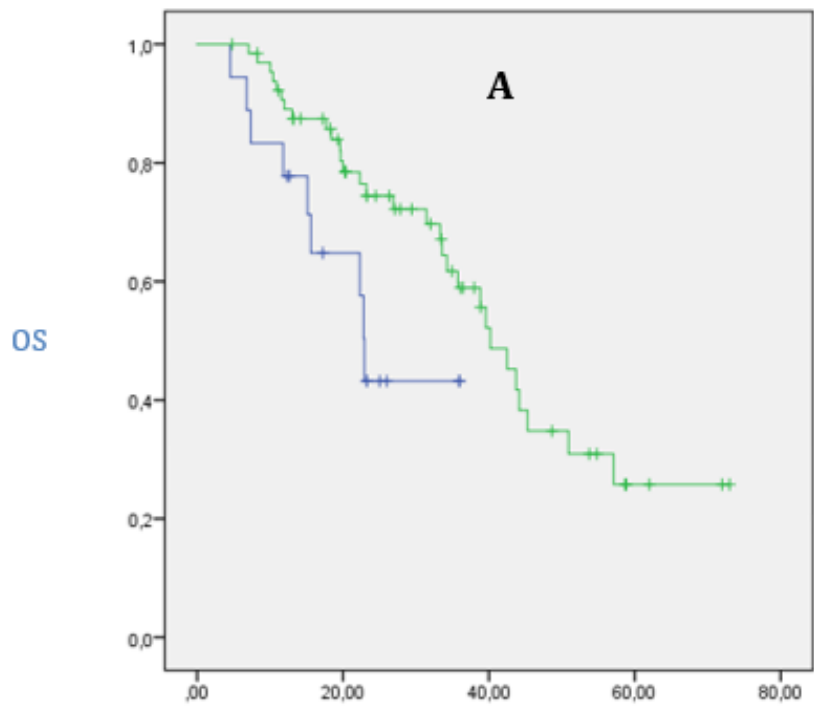

MONTH

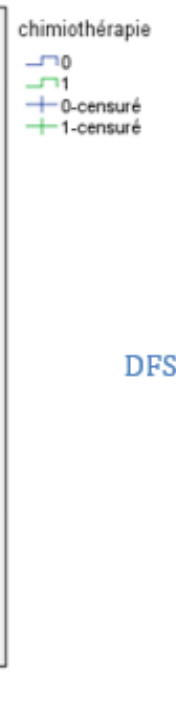

DFS

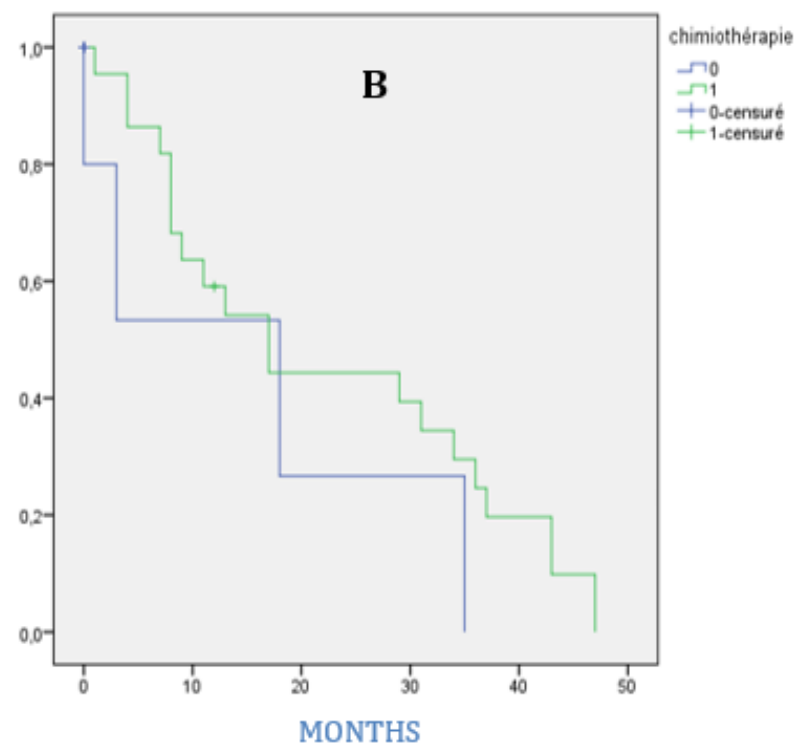

Figure 2

Comparison of OS (A) and DFS (B) between the 2 groups CA vs OBS The median of OS in AC group was $: 40$ months vs. 23 months in the OBS group $(p=0.036)$; there was The median of DFS in AC group was 18 mois vs 17 mois $(p=0,14)$ in OBS group
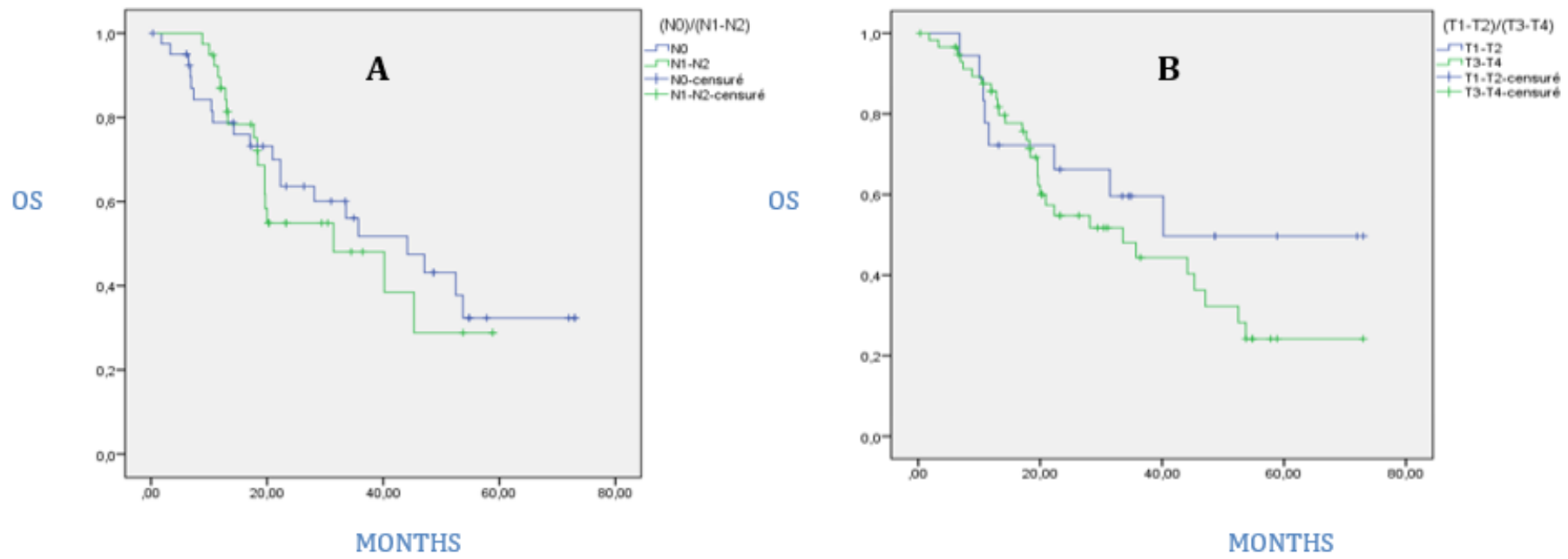

Figure 3

A: Overal survival according to the ypN subgroups, B: Overal survival according to the ypT The median OS in the ypT1-2 and ypN0 subgroups was higher than in the ypT3-4 or ypN + subgroups: (40 months vs 33 months $(p=0.3))$ and 44 months vs 31 months respectively $(p=0.6))$; 

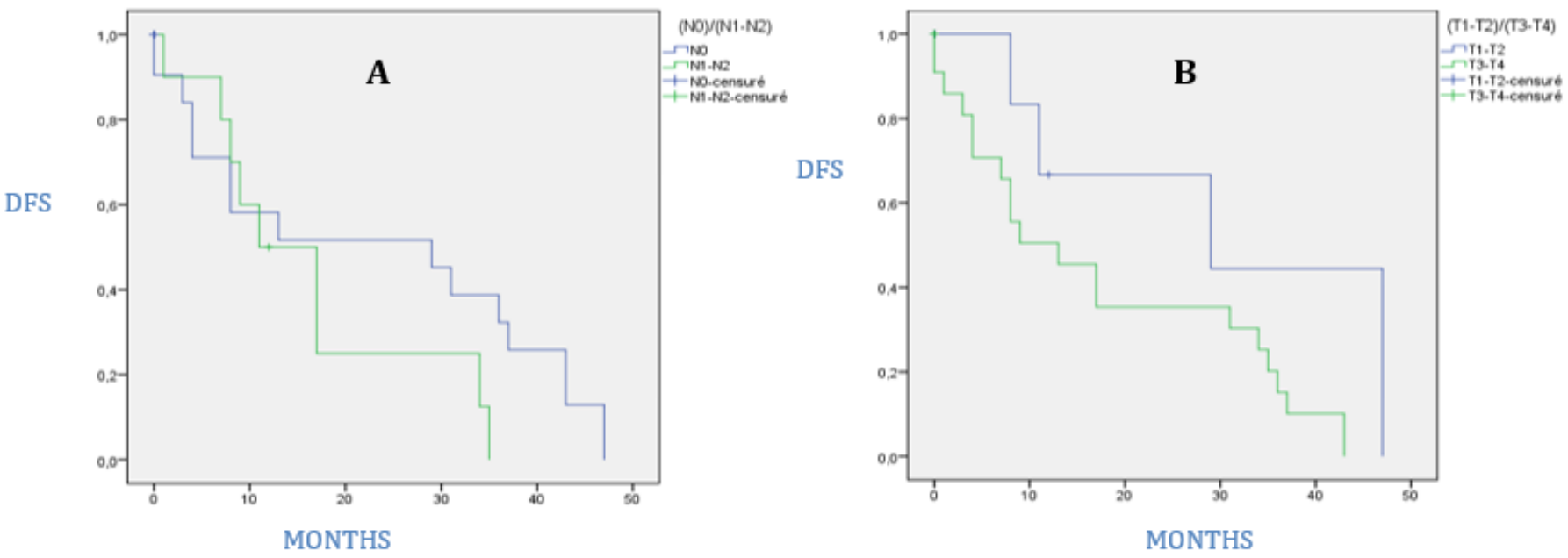

\section{Figure 4}

A: DFS according to the ypN subgroups; B: DFS according to the ypT subgroups The median of DFS was in the ypT1-2 and ypN0 group29 months vs 11 months $(p=0.05)$ and 29 months vs13 months respectively $(p=0.2)$ in the ypT3-4 or ypN+. 